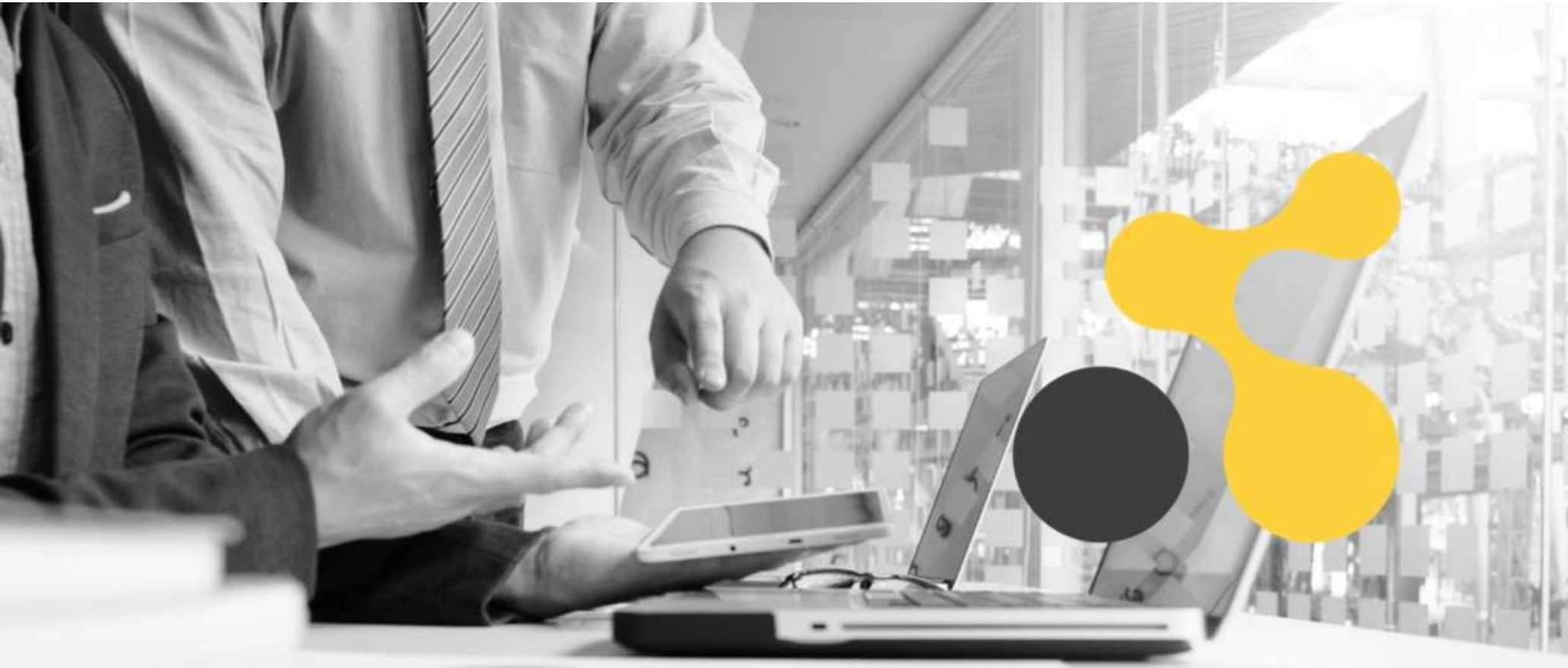

\title{
SCIPEDIA
}

\section{Factors Affecting Supervision Practice of Public Building Construction Projects in Dire Dawa Administration}

Azeb Getu, Emer Tucay Quezon², Temesgen Genie

1 Addis Ababa Science \& Technology University

2 University of the Philippines Diliman

INFORMATION

Keywords:

: construction industry project site supervision adequate supervision relative importance index

Published: 15/09/2021 


\title{
Factors Affecting Supervision Practice of Public Building Construction Projects in Dire Dawa Administration
}

\author{
Azeb Getu ${ }^{1, *}$, Emer T. Quezon ${ }^{2}$, Temesgen Genie ${ }^{1}$ \\ ${ }^{1}$ Department of Civil Engineering, Institute of Technology, Dire Dawa University, Dire Dawa, Ethiopia \\ ${ }^{2}$ Department of Civil Engineering, College of Architecture and Civil Engineering, \\ Addis Ababa Science \& Technology University, Addis Ababa City, Ethiopia \\ *Corresponding author: azi.getu2000@gmail.com, quezonet09@gmail.com \\ Received August 03, 2021; Revised September 05, 2021; Accepted September 13, 2021
}

\begin{abstract}
Proper completion of a public building construction project is dependent on the effectiveness of the construction supervision. However, it has become increasingly difficult to finish construction projects within the specified time, budget, and quality standards due to poor supervision practices. Approaches such as quantitative and qualitative research and descriptive research types were used in this study. Questionnaires survey were issued to 104 respondents, with 11 representing clients, 22 representing consultants, and 71 representing contractors. There were 33 factors identified, which were then divided into seven groups for further analysis. It was discovered that the top-ranked factors that influence construction supervision practice are: supervisors' lack of skills and experience, incompleteness and consistency in the design, lack of appropriate decision making, location of the project, material and equipment costs, a lack of construction materials supply, and effect of weather conditions. The Relative Importance Index was calculated to determine whether or not the parties agreed on the factors and ranked them according to their importance. Most respondents suggested that supervisors should receive proper training, and comprehensive and detailed drawings should be provided on time. In addition, it was discovered that the top three essential group elements affecting supervision practice of the public building project are supervisory, design, and management-related aspects.
\end{abstract}

Keywords: construction industry, project site supervision, adequate supervision, relative importance index

Cite This Article: Azeb Getu, Emer T. Quezon, and Temesgen Genie, "Factors Affecting Supervision Practice of Public Building Construction Projects in Dire Dawa Administration." American Journal of Civil Engineering and Architecture, vol. 9, no. 4 (2021): 134-141. doi: 10.12691/ajcea-9-4-2.

\section{Introduction}

The construction industry has been rapidly expanding, and it is vital to the country's prosperity. The sector was struggling to find a skilled supervisor. The supervision issues emerged due to the lack of interest of youth in the building business. Even if they joined, most of them were unskilled and had not completed the required trainings. Incompetent construction managers lead to reworked projects. It can also happen in poorer nations like Ethiopia due to poor oversight of construction projects. So, inadequate project supervision is one of the significant and critical aspects that contribute to quality loss in building projects [1].

The occurrence of building failures related to poor construction supervision has become the main challenge of low-income countries. [2], revealed that there is a significant relationship between inadequate construction supervision and unsustainable building construction practices.

If so, the construction rework would fail to complete the project on the allocated cost and time. Ethiopia is a developing country with having several people involved in construction projects. Conversely, most of the laborers are unskilled as well as unqualified. The construction project's success in completing is heavily based on the quality and skill of the supervisor [3]. Therefore, supervisors are primarily engaged in coordinating, leading, and directing the work of others to succeed in a set of objectives. The supervision contributed a significant role in the implementation of the on-site construction project. In addition, the construction supervisions were the most influential position of the construction industry on or off the site work to make or break a construction project.

Furthermore, the project site supervisor is a crucial and valuable member of the project team, transforming the project documents into a Practical facility [4]. Many projects in developing countries like Ethiopia encounter considerable time and cost overruns, fail to realize their intended benefit, or are terminated and abandoned before or after completion. Hence, the construction industry development in the lower and middle-income countries lagged far behind the industries of developed countries. Usually, the construction industry in developing countries failed to meet the expectations of governments and clients as well. Many supervisors' inability to plan the work, 
communicate with workers, and direct activities adequately are fundamentally linked to the increasing amount and cost of rework [5]. However, adequate supervision is an essential tool for the successful completion of construction projects. Hence, coordination among project participants should be enhanced to promote better site supervision [6].

Success in completing site activities, from beginning to end, relies heavily on supervision. Modern techniques and supervisory tools are provided for supervisors to improve their performance [7]. Naturally, the quality of supervision is dependent upon the supervisor's skill. A supervisor is usually given authority and responsibility for planning and controlling a group's work by close contact. An effective supervisor dealt with several skills, including management, human and leadership skills, motivation, communication, and organizational behavior [8]. Supervision has been a less significant effect on the construction project implementation during the COVID-19 pandemic as per the respondents, according to [9]. These abilities can be improved through formal training. Most of the project managers argue that formal training can improve the supervisors' skills. However, most supervisors learn their job the hard way: making mistakes and then correcting them. Although this trial and error system is considered an essential part of the training, practical experience must be supplemented by formal training to form a sound working basis. Due to the poor documentation quality, most contractors do not have reasonably accurate estimates of rework costs. Therefore, the study identified the bases for rework, repair costs, recurring formal training costs, and quality control. Adequate project supervision during the construction stage is vital. It may provide the necessary indicators to other factors that may cause a collapse of buildings, unnoticed, unchecked, un-approved the activities, and not to use specifications or standards.

The primary role of construction supervision practice is to ensure public safety by proactively identifying non-compliances at the construction sites. Currently, via control supervision of public building construction at Dire Dawa Administration, it was identified a number of noncompliance with the policies and guidelines. It should be known, the role of project supervision significantly improved the quality and safety of the public building construction, including its supervision practice. Thus, supervision quality depends on supervisors, and various factors affect supervisors' performance [10]. Supervision of the constriction operation would ensure that the aim of justifiable development is taken into consideration in all phases of construction to prevent the interest of the current and future community [11]. The supervisor's role has been significantly strengthened to ensure the quality and safety of construction work [12]. Construction supervision must ensure that sustainable development goals are taken into account in all phases of construction to protect the interests of society today and in the future [13]. Sustainability has different purposes and elements at various stages of the construction process [14], which need to be assessed during the supervision process to translate the principles of sustainable development into the construction process [15]. Therefore, the role of supervision in the public building construction site mostly needed proper supervision practice as significant activity in serving to confirm public safety and keep the benefits of society through proactively determining non-compliance at the construction fields and suggest improvement measures.

The study focused on the supervision practice of public building projects with the following objectives: (1) to identify the major factors affecting the construction supervision practice, and, (2) to evaluate the impacts of inadequate supervision practice in public building project implementation.

\section{Research Methodology}

\subsection{Study Area}

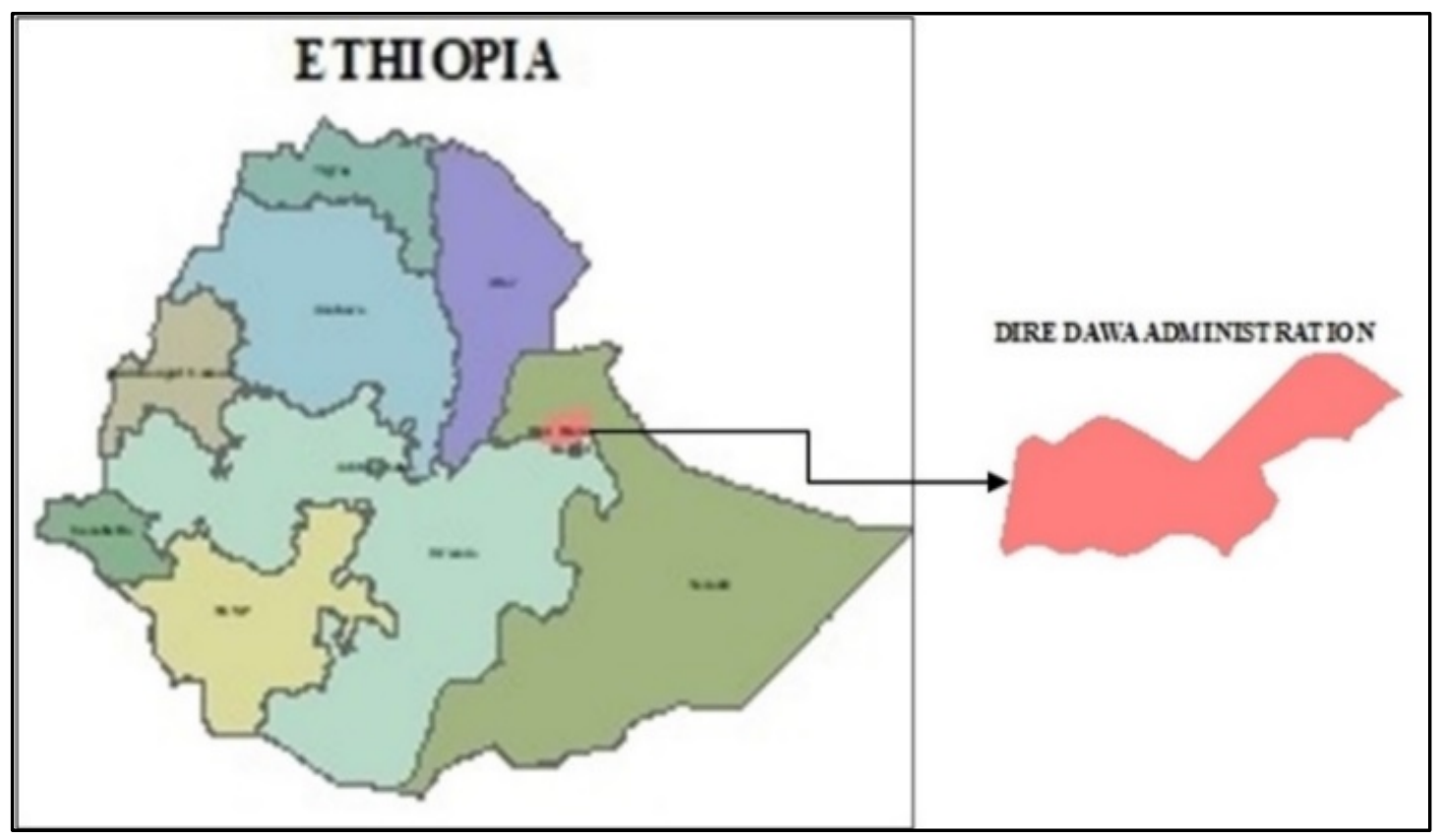

Figure 1. Map of the study area 
The study was conducted at Dire Dawa Administration on public building construction projects and found in the east-central part of Ethiopia, located on $9^{\circ} 35^{\prime} 24^{\prime \prime}$ latitude and $41^{\circ} 52^{\prime} 12$ " longitude with an elevation of $1204 \mathrm{~m}$ from mean sea level. It is positioned by 515 Kilometers to the east of Addis Ababa, 55 kilometers to the north of the historic city of Harar, and 311 kilometers to the west of Port Djibouti. It has a population of around 252,279 that was originated in 1902 by French railway contractors after the Addis Ababa Railway reached the area. This lead to a trade center between the port of Djibouti and the capital city of Addis Ababa. Administration of Dire Dawa is a chartered city administration, which entails nine (9) urban and 38 rural kebeles. Mostly, the administration has a total land size of 1559 in a square kilometer. Whereas the topographic nature is highly categorized into mountainous and flat terrain features [16].

\subsection{Study Design}

The research design is a simple blueprint used as guidance while collecting and analyzing the data. The study elaborated on both quantitative and qualitative approaches, and primary and secondary data were used as sources. Then, this study was collected data from the review of literature, questionnaires, and interviews on the public building construction projects and analyzed using Excel, SPSS v20.

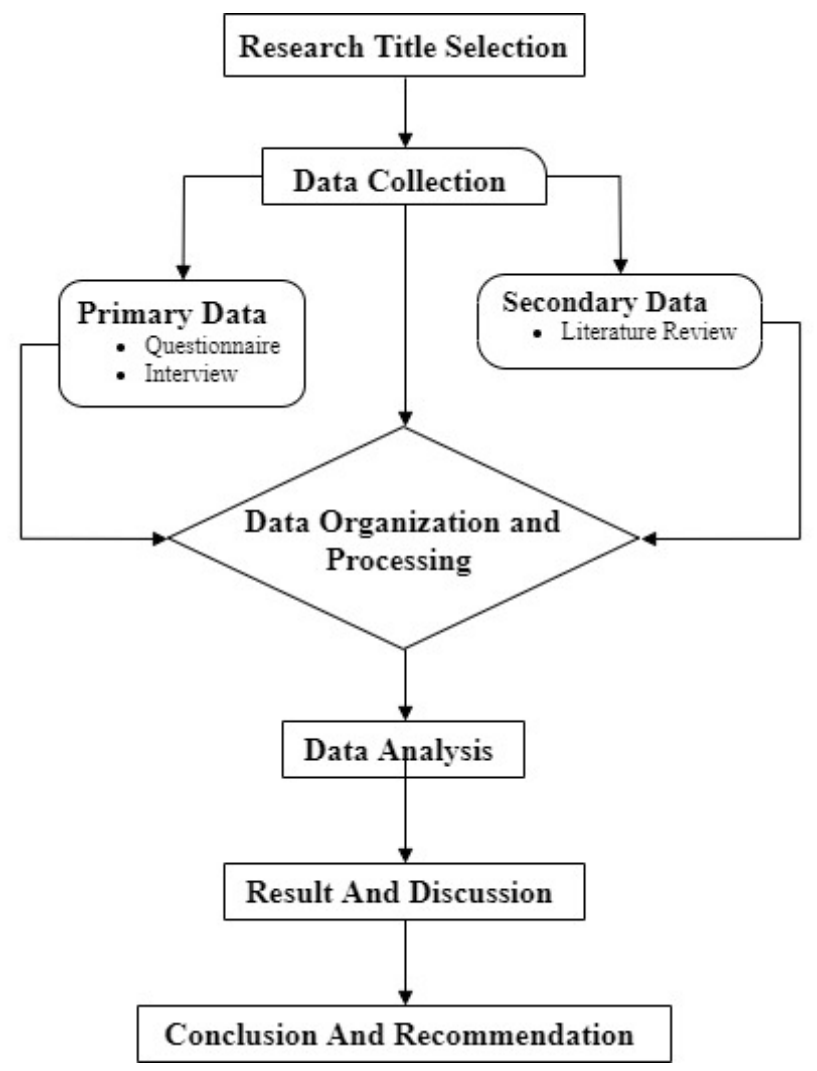

Figure 2. Research Design and Process

\subsection{Sample Size and Selection}

The population of the study comprised the professionals of public building projects in the Dire Dawa Administration. The target population included 15 clients, 30 consultants, and 95 contractors. So, it has a total population of the study of 140 respondents. The sample size was calculated using Slovin's formula $[17,19,21]$, at a 95\% confidence level with the allowable error of $5 \%$. Table 1 shows the sample frame of the respondents.

$$
\begin{aligned}
& n=\frac{N}{\left[1+N(e)^{2}\right]} \\
& n=\frac{1}{\left[1+140(0.05)^{2}\right]}=104
\end{aligned}
$$

Where:

$\mathrm{n}=$ sample size

$\mathrm{N}=$ the population size

$\mathrm{e}=$ allowable error at $95 \%$ confidence level.

\subsection{Sampling Technique}

This study used a stratified sampling technique to collect the necessary data using questionnaires and interviews with proportionate to select 11 clients out of 15 , while 71 contractors out of 95 , and 22 consultants out of 30 project consultants.

\subsection{Study Variables}

\subsubsection{Dependent Variable}

The dependent variable of the study was the level of supervision practice of public building projects in Dire Dawa Administration.

\subsubsection{Independent Variables}

The independent variables of this study are the factors affecting supervision practice of public building projects, namely; design, management, cost, health and safety, and supervision related factors.

\subsection{Data Collection Process}

The data collection process contributed an essential role in the result of the study. This study was employed questionnaires and interviews for the data collection process. Both open and closed-ended questionnaires were distributed to 80 respondents, and interviews are used to validate the finding of the questionnaire.

\subsection{Data Processing and Analysis}

The data obtained from primary and secondary data collection are analyzed using the RII method, Microsoft Excel, and SPSS v20 engaged in prioritizing the rank of relative Importance index of the variables influencing the supervision practice of public building projects in Dire Dawa Administration.

Therefore, three crucial steps were engaged to analyze the data (i.e., computing the RII value of each factor, ranking of each factor, depending on the RII value, and determining the degree of correlations in the ranking $[18,20]$. 


$$
R I I=\frac{\sum W}{A^{*} N}
$$

Where:

RII $=$ Relative Importance

$\mathrm{W}=$ Weight of each factor given by the Respondent

$\mathrm{A}=$ the highest weight (i.e. 5)

$\mathrm{N}=$ Total number of respondent

The variable among project clients, Consultants, and contractors). Likewise, the spearman Correlation coefficient is used to measuring the differences in ranking between the groups of respondents.

$$
r_{S p m}=1-\frac{6 \sum D^{2}}{n\left(n^{2}-1\right)}
$$

Where:

$r_{\text {Spm }}=$ Spearman correlation coefficient

$\mathrm{D}=$ the difference each pair of ranks

$\mathrm{n}=$ number of respondents or individuals.

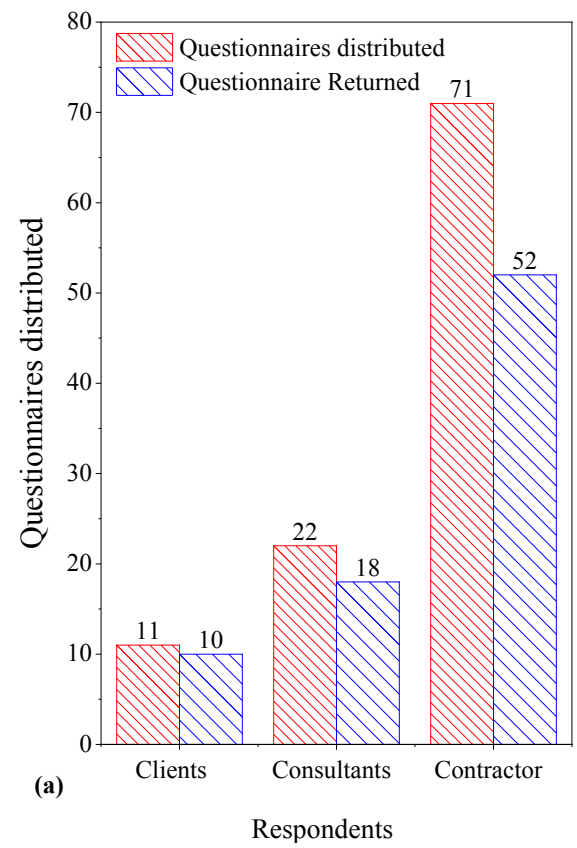

\section{Results and Discussion}

\subsection{Respondents Profile}

One hundred four questionnaires were distributed to the respondents working with different backgrounds on the public building construction projects in the Dire Dawa Administration. Out of 104 questionnaire distributed, 80 questionnaires were returned i.e. $10 \quad(90.91 \%)$ questionnaires from clients, 18 (81.81\%) from consultants and $52(73.24 \%)$ from contractors. which is adequate for the analysis, as shown in Figure 3 (a) and (b).

Table 1 and Table 2 show the respondent's overall work experience in construction projects. Most of the respondents have a different level of work experience in public building projects, as specified in Table 2 in terms of year involvement in the construction industry.

Table 3 indicates the educational background held by the respondents, namely: consultant, contractor, and client, which includes 4 (5\%) Diplomas, and 66 (75\%) BSc. Degree and 16 (20\%) MSc.

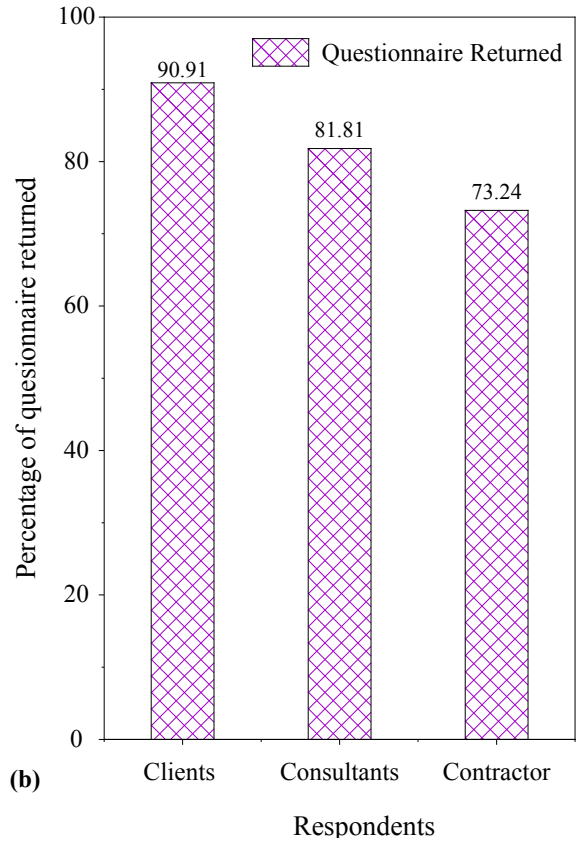

Figure 3. (a) and (b) shows questionnaire distributed and returned percentage

\begin{tabular}{|c|c|c|c|c|}
\hline Respondents' level of experience & Frequency & Percent & Valid Percent & Cumulative Percent \\
\hline $0-5$ year & 31 & 38.8 & 38.8 & 38.8 \\
\hline $6-10$ years & 33 & 41.3 & 41.3 & 80.0 \\
\hline Above 15 years & 1 & 1.3 & 1.3 & 100.0 \\
\hline Total & 80 & 100.0 & 100.0 & \\
\hline
\end{tabular}

Table 1. Respondents Work Experience in the construction industry

Table 2. Work Experience in building construction

\begin{tabular}{lcccc}
\hline Respondents' level of experience & Frequency & Percent & Valid Percent & Cumulative Percent \\
\hline 0-5 years & 52 & 65.0 & 65.0 & 31.3 \\
6-10 years & 25 & 31.3 & 2.5 & 2.5 \\
11-15 years & 2 & 1.3 & 1.3 & 96.3 \\
Above 15 years & 1 & 100.0 & 100.0 \\
Total & 80 & & 100.0 \\
\hline
\end{tabular}


Table 3. Respondents educational status

\begin{tabular}{lcccc}
\hline Educational status & Frequency & Percent & Valid Percent & Cumulative Percent \\
\hline diploma/advanced diploma & 4 & 5.0 & 5.0 & 75.0 \\
BSc & 60 & 75.0 & 5.0 & 20.0 \\
MSc & 16 & 20.0 & 100.0 & 100.0 \\
Total & 80 & 100.0 & 100.0 \\
\hline
\end{tabular}

Table 4. Respondents field of specialization

\begin{tabular}{|c|c|c|c|c|}
\hline Field of Specialization & Frequency & Percent & Valid Percent & Cumulative Percent \\
\hline Civil engineering & 43 & 53.8 & 53.8 & 53.8 \\
\hline Construction technology and management & 17 & 21.3 & 21.3 & 75.0 \\
\hline structural engineering & 3 & 3.8 & 3.8 & 78.8 \\
\hline Architectural engineering & 9 & 11.3 & 11.3 & 90.0 \\
\hline Others & 8 & 10.0 & 10.0 & 100.0 \\
\hline Total & 80 & 100.0 & 100.0 & \\
\hline
\end{tabular}

The field of specialization held by respondents from consultant, contractor, and the client as depicted in Table 4 involves 43(53.8\%) Civil Engineering, 17(21.3\%) Construction Technology and Management, 9(11.3\%) Architecture, 3(3.8\%) structural engineering and 8(10\%) others.

\subsection{Factors Affecting Construction Supervision Practice}

\subsubsection{Supervision Related Factors}

Figure 4 (a) shows the rank of supervision-related factors that affect construction supervision practice from the calculated RII values.

The client ranked lack of skill and experience, lack of standard and guidelines, and lack of communication and follow up in the first, second, and third places with the RII values equal $0.828,0.785$, and 0.698 , respectively. These factors are essential for the clients because lack of skill and experience, lack of standard and guidelines, and lack of communication and follow up mainly affects the supervision practice in the public building construction as shown in Figure 4 (a). lack of standards and guidelines, lack of cooperation among site staff, and lack of communication and follow up with RII values of 0.735 , 0.730 , and 0.680 have been ranked in the first, second, and third position via the consultant. Therefore, these factors are highly influencing the supervision practice in public

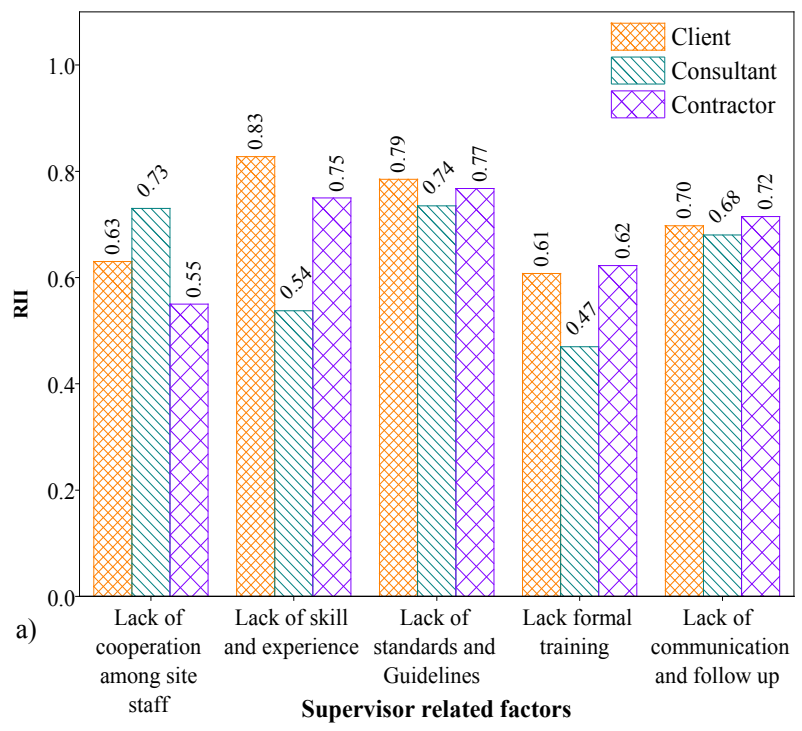

building projects in dire Dawa administration. Contactors ranked lack of standard and guidelines, lack of skill and experience, and lack of communication and follow up first, second and third place with RII values equal to 0.768 , 0.750 , and 0.715 . These factors are significant factors affecting construction supervision practice.

\subsubsection{Design-related Factors}

Figure 4 (b) shows the rank of design-related factors that affect construction supervision practice from the calculated RII values. According to the clients' Incompleteness and Inconsistency of design factor with RII value 0.878 placed as first, Drawings with lack of Details factor with RII value of 0.855 placed as second and lack of skill in design factor with RII value equal to 0.820 placed as third. Hence, incompleteness and inconsistency of Design, drawing with lack of detail, and lack of skill in Design significantly influence the supervision practice of public building projects. Incompleteness and Inconsistency of Design, unclear site drawings, and lack of skill in Design have been ranked by the consultants' respondents in the first, second, and third positions with RII values equal to $0.803,0.755$, and 0.755 , respectively. Incompleteness and Inconsistency of Design, unclear site drawings, and lack of skill in Design affect the project supervision practice. Whereas, Contactors ranked Unclear site drawings, Incompleteness, and Inconsistency of Design and Drawings with lack of Details.

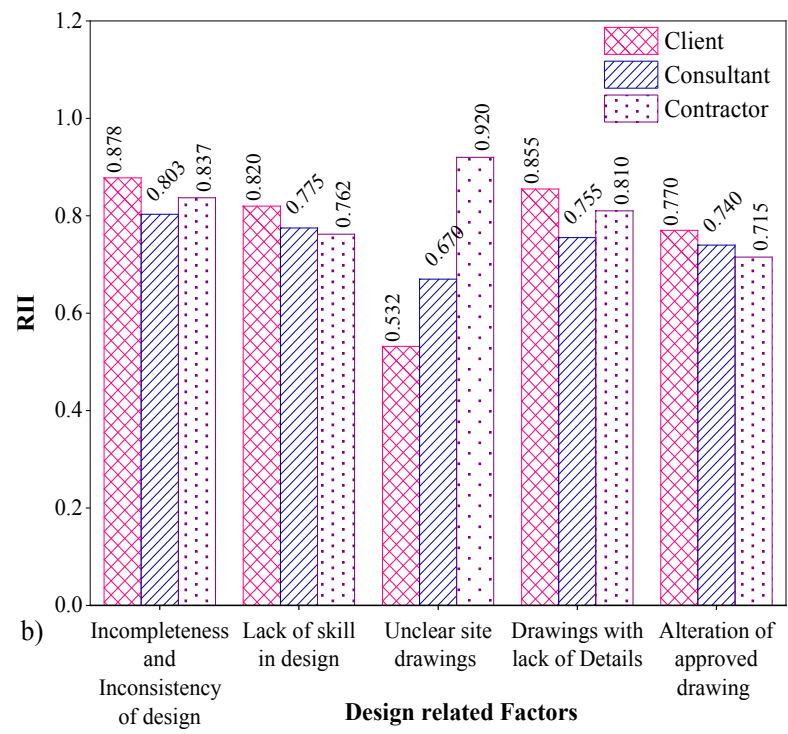

Figure 4. (a) and (b) shows supervision and design-related factors by RII values 


\subsubsection{Management Related Factors}

The most significant factors that the clients, consultants, and contractors agreed on as the main influencing factors of supervision practice in public building projects were: Lack of appropriate decision; Lack of full-time consultant involvement; Professional incapability, and Lack of cooperation based on the RII values.

\subsubsection{Health and Safety Related Factors}

Ignorance of safety equipment has been ranked via the client's respondents in the second position with RII equal 0.698 . It has been ranked by the consultant's respondents in the second position with RII equal 0.673 and has been ranked by the contractor's respondents in the first position with RII equal 0.798 . This factor can be designated as vital for three parties, and it has a similar rank for all parties as it significantly affects project supervision practice.

\subsubsection{Financial Related Factors}

The cost of materials and equipment ranked first by all respondents (i.e., client, consultant, and contractors) from finical related factors. The cost of materials and equipment change for a public building project is mainly due to the organization's liquidity, which affects the clients ' liquidity and the contractors' profit rate.

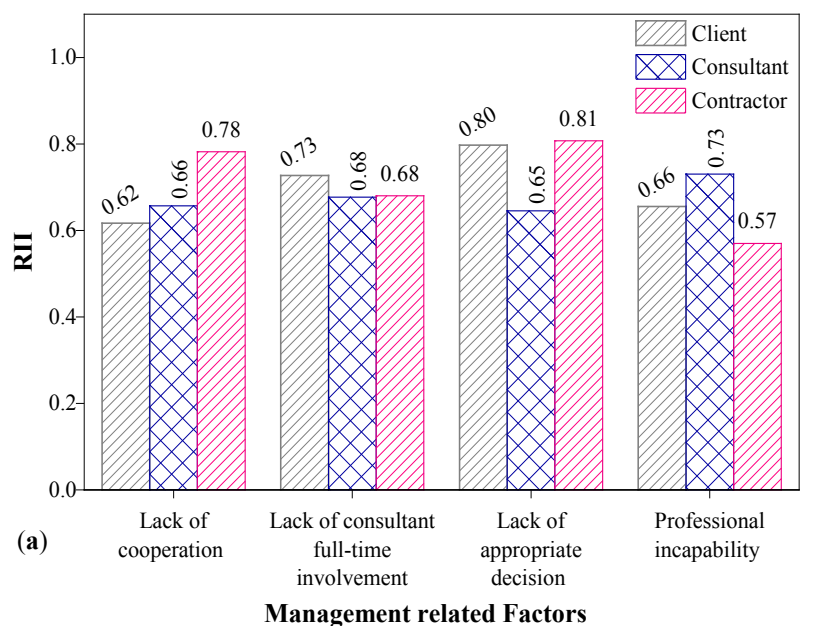

\subsubsection{Material Related Factors}

The consultant rated the quality of materials was ranked 1 st by the consultant and 2 nd by the client with RII values equal 0.828 and 0.853 . It was ranked 4 th by the contractors with an RII equal to 0.668 . It is not surprising that this factor is more important to the consultants than others because this quality control is one of the most critical tasks for the consultant on the construction site of the public building project. On the other hand, an increase in material price has been rated 1 st by contractors, $3 \mathrm{rd}$ by the consultant, and 5 th by the client with RII values of $0.820,0.715$, and 0.665 , respectively. Therefore, the increase in material price significantly affected the contractor rather than the consultant and client in the supervision practice of public building projects in the Dire Dawa Administration.

\subsubsection{External-Related Factors}

According to all respondents, the climate condition at the site was ranked first among the external related factors, with an average RII value equal to 0.772 . This factor is essential for clients, consultants, and contractors as it immediately affects public building projects' supervision practice.

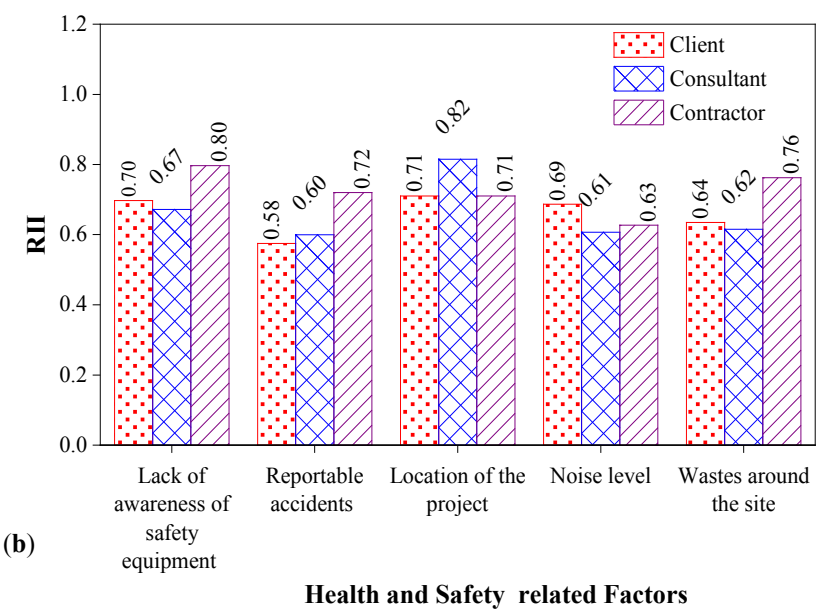

Figure 5. (a) and (b) shows management and health and safety-related factors by RII values
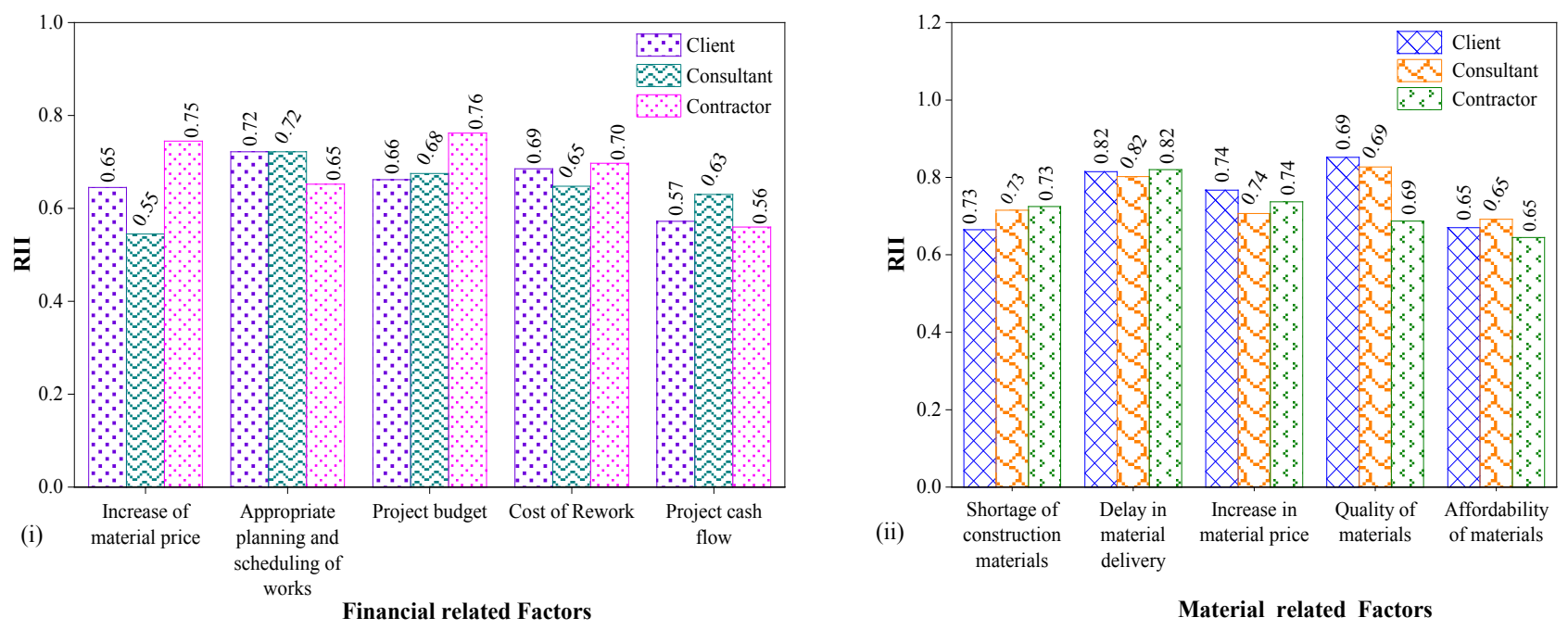

Figure 6. (a) and (b) indicated the RII value of Financial and Material related factors 


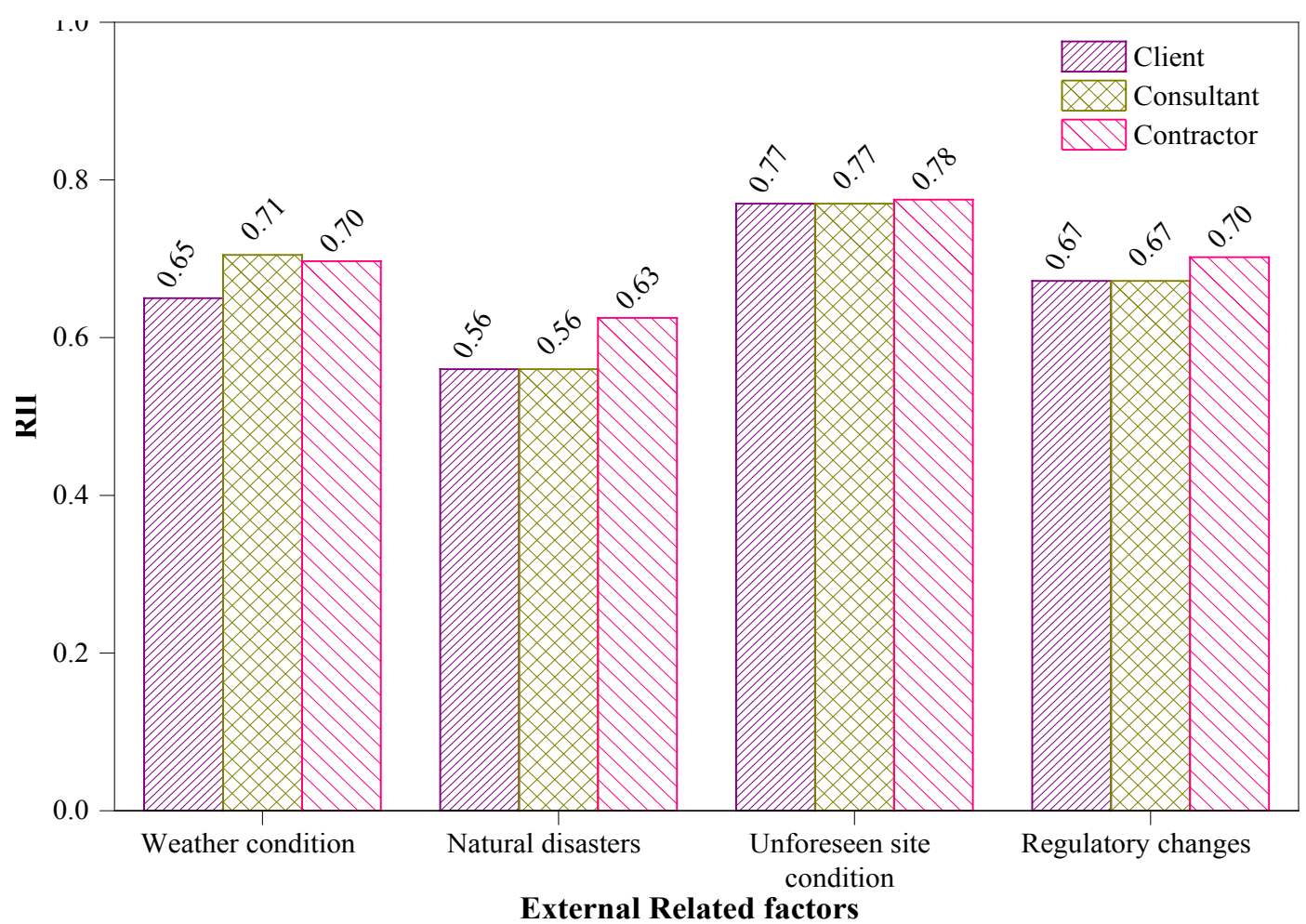

Figure 7. Relative Importance Index on External Related factors

Table 5. Relative Importance Index on Group of factors

\begin{tabular}{|c|c|c|c|c|c|c|c|c|}
\hline \multirow{2}{*}{ Variables (Group of Factors) } & \multicolumn{2}{|c|}{ Client } & \multicolumn{2}{|c|}{ Consultant } & \multicolumn{2}{|c|}{ contractor } & \multirow{2}{*}{ Weighted Average of RII } & \multirow{2}{*}{ Overall Rank } \\
\hline & RII & R1 & RII & $\mathrm{R} 2$ & RII & R3 & & \\
\hline Supervision-related factors & 0.965 & $1^{\text {st }}$ & 0.773 & $2^{\text {nd }}$ & 0.863 & $2^{\text {nd }}$ & 0.860 & $2^{\text {nd }}$ \\
\hline Design-related factors & 0.883 & $2^{\text {nd }}$ & 0.883 & $1^{\mathrm{st}}$ & 0.905 & $1^{\mathrm{st}}$ & 0.890 & $1^{\mathrm{st}}$ \\
\hline Management-related factors & 0.790 & $3^{\text {rd }}$ & 0.690 & $4^{\text {th }}$ & 0.725 & $5^{\text {th }}$ & 0.735 & $3^{\text {rd }}$ \\
\hline Health \& Safety-related factors & 0.748 & $4^{\text {th }}$ & 0.700 & $3^{\text {rd }}$ & 0.648 & $6^{\text {th }}$ & 0.698 & $4^{\text {th }}$ \\
\hline Financial-related factors & 0.638 & $5^{\text {th }}$ & 0.663 & $5^{\text {th }}$ & 0.845 & $3^{\text {rd }}$ & 0.715 & $5^{\text {th }}$ \\
\hline External-related factors & 0.595 & $7^{\text {th }}$ & 0.610 & $7^{\text {th }}$ & 0.598 & $7^{\text {th }}$ & 0.601 & $7^{\text {th }}$ \\
\hline
\end{tabular}

Note: R1, R2 \& R3, columns ranking.

The design-related factor was ranked first with a weighted average of RII value equal to 0.890 . The supervision-related factor group was ranked second with the weighted average of RII value equal to 0.965 by all respondents. The Management-related factor and Health and Safety related factor group has been ranked third and fourth by the respondents, namely clients, consultants, and contractors, with a weighted average of RII values of 0.735 and 0.698 , as Table 5 shows.

Therefore, these group factors highly influenced the supervision practice of public building projects compared with others.

\subsection{Correlation on Significant Factors Affecting Supervision Practice}

Spearman's rank gave the researcher a numerical value on the degree of correlation or non-correlation. It is a relatively straightforward analysis for those who are not wholly confident in their mathematical skills. Value can range from -1 to +1 . Table 6 indicates the summarized correlation results [9]. It shows the summarized Spearman correlation coefficient suggested that there is a strong correlation between all groups of factors. It implies, most of respondents have similar perception of the factors affecting construction supervision practice.

Table 6. Correlation result of respondents

\begin{tabular}{lcc}
\hline Respondents & $r_{S p m}=1-\frac{6 \sum D^{2}}{n\left(n^{2}-1\right)}$ & Relation of the respondents \\
\hline Client Vs. Consultant & 0.999 & Strong \\
Consultant Vs. Contractor & 0.997 & Strong \\
Client Vs. Contractor & 0.998 & Strong \\
\hline
\end{tabular}




\section{Conclusion}

The building industry is vital to the development and completion of society's goals. Clients, contractors, consultants, stakeholders, regulators, and the economy impacted all construction project management. This research seeks to determine the characteristics that influence public building project supervision. This study considered 33 criteria based on a literature review. In addition to the factors listed above, some are included based on professional suggestions. The study key groups included supervision, Design, management, health and safety, financial, material, and external. The respondents rated the supervision-related factor category second overall, with an average weighted RII of 0.860 . First place went to the Design related factor group, followed by the management-related factor group (0.735) and health \& safety-related factor group (0.698). These are the Dire Dawa Administration's most influential groups in public building project supervision. A complete design, experienced and skilled supervisors, forecasting unpredictable conditions, on-time decisions, health \& safety, equipment and awareness-raising, supervisor training are suggested measures to improve construction supervision practice in public building projects.

\section{Acknowledgments}

The authors would like to acknowledge Dire Dawa Institute of Technology for the limited support extended for this research.

\section{References}

[1] S. Hai, J. Wang, D. Wu, and Q. Bao, "Evaluating the Quality of Project Supervision Engineers - A Case Study in China," Int. J. Constr. Manag., vol. 2, no. 1, pp. 13-23, 2002.

[2] M. Agwu, "Perception Survey of Poor Construction Supervision and Building Failures in Six Major Cities in Nigeria," Br. J. Educ. Soc. Behav. Sci., vol. 4, no. 4, pp. 456-472, 2014.

[3] S. G. Dalibi, "Resultant Effects of Poor Supervision in Construction Projects in Nigeria," 6th Build. Constr. Econ. Round Table Organised by Quant. Surv. Regist. Board Niger. Under Theme "Professional Issues Challenges Build. Collapses Niger., pp. 1-22, 2015.

[4] S. R. Rounds JL, Construction Supervision. John Wiley \& Sons; 2011.

[5] Baguma Abel, "The Level of Supervision and Quality of Building Structures in Nakasongora District A case Study of Lwabyata SubCounty," May 2011.
[6] J. K. Hackman, A. Acheampong, K. Agyekum, and J. Ayarkwa, "Factors Affecting Site Supervision in the Ghanaian Construction Industry," Conference Pap., no. January, pp. 1-13, 2016.

[7] S. Shahraki, E. Saghatforoush, and A. Z. Ravasan, "Identification and Classification of Factors Affecting the Performance of Building Supervisor Engineers for Construction Industry," J. Eng. Proj. Prod. Manag., vol. 8, no. 2, pp. 65-74, 2018.

[8] S. Alwi, K. Hampson, and S. Mohamed, "Effect of quality supervision on rework in the Indonesian context," Asia-Pacific Build. Constr. Manag. J., vol. 6, January, pp. 2-6, 2001.

[9] E. T. Quezon and A. G. Ibanez, "Effect of Covid-19 Pandemic in Construction Labor Productivity: A Quantitative and Qualitative Data Analysis," Am. J. Civ. Eng. Archit. Vol. 9, 2021, Pages 23-33, vol. 9, no. 1, pp. 23-33, 2021.

[10] R. S. Maheshkumar and S. K. Purva, "Impact of Supervision on Rework in Construction In," Int. J. Recent Innov. Trends Comput. Commun., vol. 4, no. 1, pp. 1-7, 2016.

[11] L. Chang, Y. Wang, G. Feng, and L. Wang, "Research on problems and solutions in construction quality supervision of construction projects," Smart Constr. Res., vol. 2, no. 3, pp. 1-5.

[12] Z. Ma, S. Cai, N. Mao, Q. Yang, J. Feng, and P. Wang, "Construction quality management based on a collaborative system using BIM and indoor positioning," Autom. Constr., vol. 92, no. September 2017, pp. 35-45, 2018.

[13] M. S. Bajjou, A. Chafi, A. Ennadi, and M. El Hammoumi, "The practical relationships between lean construction tools and sustainable development: A literature review," J. Eng. Sci. Technol. Rev., vol. 10, no. 4, pp. 170-177, 2017.

[14] M. Abdellatif and A. Al-Shamma'a, "Review of sustainability in buildings," Sustain. Cities Soc., vol. 14, no. 1, pp. 171-177, 2015.

[15] I. Othman, M. Kamil, R. Y. Sunindijo, M. Alnsour, and A. F. Kineber, "Critical success factors influencing construction safety program implementation in developing countries," J. Phys. Conf. Ser., vol. 1529, no. 4, 2020.

[16] B. Worku, "Historical-Sociology of Interaction in the city of Dawa Dawa: The case of Oromo-Somali ethnic groups," International Journal of Scientific and Research Publications, Volume 7, Issue 3, March 2017, p. 235-240, 2017.

[17] E. Stephanie, "2003. Slovin's formula sampling techniques. Houghton-Mifflin, New York, USA," Slovin's formula Sample. Tech.

[18] R. Abidali and Y. Ali, "Factors Affecting on the Performance of Contractors in Constriction Project: Bagdad, Iraq," J. Univ. Babylon Eng. Sci., no. 26, p. 2018, 2018.

[19] S. Molla, E. T. Quezon, E. Mekonnen, W. Ararsa, D. Gudissa, A. Tibebu. "Factors Affecting the Performance in the Implementation of Government Building Construction Projects: A Case Study in Bole Sub- City of Addis Ababa." Xi'an Dianzi Keji Daxue Xuebao/Journal of Xidian University, 14(11) 2020, 247-256.

[20] A. Fromsa, W. Ararsa, E. T. Quezon. "Effects of Poor Workmanship on Building Construction and Its Implication to Project Management Practice: A Case Study in Addis Ababa City." Xi'an Dianzi Keji Daxue Xuebao/Journal of Xidian University. 14(9), 2020.

[21] B. Sitota, E. T. Quezon, W. Ararsa. "Assessment on Materials Quality Control Implementation of Building Construction Projects and Workmanship: A Case Study of Ambo University." Xi'an Dianzi Keji Daxue Xuebao/Journal of Xidian University. 15(8): 2021, 138-155. 